\title{
PROPERTY OF A HÖLDER-TYPE INEQUALITY AND ITS APPLICATION
}

\section{JING-FENG TIAN}

Abstract. In this paper, we present a property of a Hölder-type inequality which is due to Tian, and then we obtain the similar property of Hölder's inequality. Moreover, we give a new refinement of Hölder's inequality. As application, we offer a new property of Minkowski-type inequality, and then we obtain a new refinement of Minkowski's inequality.

Mathematics subject classification (2010): 26D15, 26D10.

inequality.

Keywords and phrases: Hölder-type inequality, Hölder's inequality, Minkowski-type inequality, Minkowski's

\section{REFERENCES}

[1] S. Abramovich, J. PeČArić And S. VAroš Anec, Sharpening Hölder's and Popoviciu's inequalities via functionals, Rocky Mt. J. Math. 34 (2004), 793-810.

[2] S. Abramovich, J. PEČARIĆ And S. VARoŠAneC, Continuous sharpening of Hölder's and Minkowski's inequalities, Math. Inequal. Appl. 8, 2 (2005), 179-190.

[3] E. F. Beckenbach And R. Bellman, Inequalities, Springer-Verlag, Berlin, 1983.

[4] L. Horváth AND J. PEČARIĆ, A refinement of the discrete Jensen's inequality, Math. Inequal. Appl. 14, 4 (2011), 777-791.

[5] K. Hu, On an inequality and its applications, Sci. Sinica 24 (1981), 1047-1055.

[6] K. Hu, On an inequality and its applications, J. Jiangxi Norm. Univ. 18, 4 (1994), 330-333.

[7] B. IVAnković, J. PEČARIĆ And S. VARošAnec, Properties of mappings related to the Minkowski inequality, Mediterr. J. Math. 8, 4 (2011), 543-551.

[8] J. Lu, K. WU AND J. Lin, Fast full search in motion estimation by hierarchical use of Minkowski's inequality, Pattern Recogn. 31 (1998), 945-952.

[9] J. Matkowski, A converse of the Hölder inequality theorem, Math. Inequal. Appl. 13, 1 (2009), 21-32.

[10] B. Mond And J. E. PEČARIĆ, On converses of Hölder and Beckenbach inequalities, J. Math. Anal. Appl. 196 (1995), 795-799.

[11] L. NikOlOVA AND S. VAROŠ ANEC, Refinements of Hölder's inequality derived from functions $\psi_{p, q, \lambda}$ and $\phi_{p, q, \lambda}$, Ann. Funct. Anal. 2, 1 (2011), 72-83.

[12] J. E. PEČARIĆ, Improvements of Hölder's and Minkowski's inequalities, Mat. Bilten (Skopje) 17 (1993), 69-74.

[13] J.-F. TIAn, Extension of Hu Ke's inequality and its applications, J. Inequal. Appl. 2011 (2011), 77. 